\title{
A ARQUITETA MIRANDA MARTINELLI MAGNOLI
}

\section{MIRANDA MARTINELLI MAGNOLI, ARCHITECT}

Fábio Mariz Gonçalves

Professor doutor da Faculdade de Arquitetura e Urbanismo da Universidade de São Paulo (FAUUSP).

E-mail:fabiomgoncalves@uol.com.br 


\title{
RESUMO
}

Apresenta-se Miranda Martinelli Magnolli como arquiteta consciente da importância da formação e das competências do arquiteto para o enfrentamento das questões do projeto da paisagem e do espaço livre. Sempre atenta ao papel fundamental do desenho no processo de criação, não descuida dos compromissos técnicos e formais do projeto. Por fim, salienta-se que a profissional e a professora guardam coerência e complementaridade, manifestadas nas ricas discussões que conduz e em sua inabalável postura ética.

\section{Palavras-chave: Arquitetura, projeto, exercício profissional, desenho.}

\begin{abstract}
Miranda Martinelli Magnolli can be introduced as an architect who is aware of the architect's education and proficiency importance while confronting issues such as landscape and open space projects. Always commited to the fundamental role of design in the creative process, she does not disregard the project's technical and formal rules. Finally, we stress that the architect and the teacher share the same coherency and complementarity as a professional, expressed through the fruitful discussions she has and her steadfast ethical behavior.
\end{abstract}

Key words: Architecture, project, professional works, drawing. 


\title{
A ARQUITETA MIRANDA MARTINELI MAGNOLLI
}

\author{
MIRANDA MARTINELI MAGNOLI, ARCHITECT
}

\section{A Arquiteta}

Nesta oportunidade quero falar sobre um aspecto fundamental da professora Miranda: seu lado profissional, ela enquanto arquiteta.

Fui seu aluno na graduação, desde o primeiro semestre. Fiz as disciplinas obrigatórias, as optativas e acabei estreitando os laços com a professora, aos poucos ficamos amigos. Nessas disciplinas aprendi o que era importante para ela, entendi que o desenho enquanto instrumento de reflexão e de expressão é, com certeza, uma de suas maiores preocupações.

Lembro de ouvi-la contar, mais de uma vez, uma história segundo a qual ela teria recebido um elogio do professor Artigas, de quem era fã. Ele havia comentado que ela desenhava muito bem, ao que um colega teria arrematado "ela tem boa mão" e o professor corrigido, "o desenho não se faz na mão e sim na cabeça, para desenhar tem que ter cabeça".

Ela, por concordar com a afirmação do mestre, busca nas várias acepções da palavra desenho o pleno exercício da profissão do arquiteto. Nas disciplinas gastávamos horas discutindo sobre os desenhos, corrigindo-os. Quando falávamos demais, ela arrematava "quero ver desenhos", perguntava: "vocês já encontraram o desenho que dê conta de todas suas expectativas?". Nos seminários, para nosso desespero, era comum perguntar a um colega o que o desenho do outro Ihe dizia.

Essa preocupação estabelecia que o desenho era o território e a obrigação do arquiteto. Assim, não erro ao garantir que o desenho e a arquitetura entraram em sua vida muito antes da paisagem e do paisagismo. Por toda uma vida dedicada à consolidação do paisagismo, enquanto atribuição do arquiteto ela nunca deixou de chamar-se arquiteta, nunca viu outra razão para esta posição se não o de entender que apenas o arquiteto é instrumentado para enfrentar com o desenho a organização do espaço e do território.

Talvez por respeito às várias condicionantes as quais pesam sobre o desenho, ela nunca fez parecer que o desenho é uma coisa banal ou simples. Embora desenhe muito bem, ela sabe que o bom desenho nasce do suor, da investigação, depois da especulação de várias alternativas e de seu debate.

Não se apresentava como aqueles arquitetos de outras gerações os quais querem fazer parecer que o desenho veio como uma inspiração divina e fácil. Não é das que acredita no desenho inquestionável, na liberdade de criação, mas sim no permanente questionar e na responsabilidade do traço.

Mesmo como pesquisadora a arquiteta prevalece. Em todas as oportunidades de discussão acerca dos temas de pesquisa na pós-graduação várias vezes notei como o fim maior era o projeto, suas possibilidades e aperfeiçoamento. Ela sempre preferiu os temas os quais abram oportunidades 
de crítica e propostas de projeto. Raramente a vi dedicar-se às paisagens mais consolidadas, aos estudos mais teóricos, às reflexões mais distantes das possibilidades de intervenção concreta e transformadora do projeto.

Depois de formado, trabalhei em seu escritório por poucos meses. Nesse tempo pude verificar com que cuidado verificava a espessura de cada traço, o alinhamento de cada chamada normografada, a escolha de cada cor para as legendas. Seu preciosismo e exigência só encontravam limites no prazo e na capacidade da equipe. Os desenhos tinham de ficar informativos, perfeitos e, sobretudo, bonitos.

Lembro de vê-la desenhando cada uma das mais de dez opções para um simples desenho de piso externo. Todas as versões coloridas e completas, como se pretendesse apresentar para o cliente.

Anos mais tarde, já com meu escritório, algumas vezes fomos contratados para "passar para o CAD" alguns desenhos seus. Os desenhos, vindos por fax, limitados na altura pelo equipamento, impressionavam pela qualidade do traçado e pelo domínio das variáveis. Detalhes completos e rigorosos de soleiras, bancos e floreiras, estabelecendo cada componente e seus papéis.

Poucos anos depois contratou um profissional para redesenhar no CAD os desenhos que fazia. Incomodada com esta mediação, pediu ao meu sócio, Luis Mauro Freire, para ensiná-la a desenhar no computador. Quantos arquitetos de sua geração tiveram a paciência e disposição para aprender a desenhar no CAD? Lembro de alguns destes desenhos, os quais pudemos ver na tela, apresentavam alguns problemas de execução como layers e linhas sobrepostas, mas quando plotados mantinham o frescor e a qualidade de um desenho à mão - pois como já foi dito, o desenho se faz na cabeça e não com o instrumento.

\section{A Profissional}

Em 2000 a Empresa Municipal de Urbanização - Emurb - contratou os arquitetos Alberto Botti e Miranda Magnoli para desenvolverem o projeto da Operação Urbana Água Espraiada.

Ambos entenderam que era mais eficiente constituírem uma equipe, externa ao escritório Botti e Rubin, para desenvolver o projeto. Então, convidaram-me, meu sócio Luis Mauro e a arquiteta Ana Maria Antunes Coelho para trabalharmos com eles na proposta.

Foi um trabalho conjunto articulado entre nós ${ }^{1}$ e a equipe da Emurb. Desenvolvemos uma ampla discussão sobre todo o material que a Emurb já tinha desenvolvido sobre esse tema. Discutimos com a Secretaria Municipal de Planejamento - Sempla - e com os demais órgãos municipais de planejamento o papel e o desenho da avenida dentro do sistema viário da metrópole.

Tanto Miranda como Botti, nessa ocasião, não agiam como coordenadores da equipe. Embora assumissem as responsabilidades diante da Emurb, colocavam-se tão abertos ao debate e à discussão que deixavam cada membro da equipe à vontade para se manifestar. Foi surpreendente ver dois arquitetos amigos, com tanta experiência e responsabilidade, colocarem-se tão intensa e abertamente em um projeto.

Era notável o prazer da construção coletiva de uma proposta que não era vista como produto de autoria individual. Ninguém tinha a exata idéia do produto final, as respostas estavam todas para serem descobertas, estávamos em um território novo, em um mundo novo, como forma e conteúdo. Muitas vezes, questiona-se, na graduação, a pedagogia do "aprender fazendo", 104 da repetição do ato do projeto como estratégia didática. No projeto da Água Espraiada pude comprovar que toda a equipe aprendeu muito ao fazer o projeto em equipe.

Miranda participou de todos os aspectos do processo, em parte por responsabilidade, em parte por rigor e exigência e, em parte, por simples entusiasmo. 
Esteve nas visitas a campo nas quais vistoriamos todas as praças, canteiros e espaços livres existentes em toda a área. Estava conosco nas visitas à Americanópolis, nas favelas e vielas mais estreitas e precárias da região.

Participou de todas as reuniões da equipe, externas e internas. Nas reuniões com a Sempla, com a Emurb, com a Associação Defenda São Paulo e com cada agente envolvido.

Acompanhou cada desenho. Verificou cada plotagem. Questionava a espessura dos traços, a definição das legendas, a especificação das cores e a organização das linhas de chamada. Cobrava que cada membro estivesse entendendo e concordando com cada aspecto do projeto. Era a arquiteta, a coordenadora e, mesmo com os prazos apertados, a professora que explica e ensina cada aspecto da profissão.

mais impressionante era perceber que as decisões coletivas eram debatidas e questionadas por todos até construirmos um consenso, uma idéia comum. Depois de encontrada a resposta, o desenho coletivo era defendido por todos, especialmente por Miranda e por Botti, como se fossem apenas deles. Muitas vezes tivemos de fazer equipes inteiras da Sempla e da CET reverem suas expectativas e idéias. Nessas ocasiões não seriam outros os debatedores, eram eles os quais, com habilidade e autoridade, argumentavam, questionando as bases e os conceitos que fundamentavam velhas práticas e regras.

Não é a todo o momento que se faz um projeto de operação urbana. Não é de modo arrogante que se faz um projeto de tão grande envergadura, e desmontam-se resistências e oposições. Acredito que ao fim dos trabalhos Emurb, Sempla e SPTrans estavam convertidas ao projeto, e suas equipes, mais do que atendidas, sentiam-se co-autoras das propostas.

Com esse trabalho acabamos construindo consensos, revendo e, muitas vezes, incorporando tudo o que já estava proposto para a avenida e seu entorno.

projeto assumia compromissos sociais e ambientais os quais foram defendidos com convicção em todos os momentos. Em complexas negociações, como as que foram necessárias ao longo do processo, é fundamental ter clareza de princípios, assumir clara postura ética acerca da hierarquia das questões.

No que se refere à postura ética do profissional, ficou claro a todos da equipe que nem Miranda nem Botti transigiram. Botti defendia o acesso livre e democrático às informações para todos os profissionais do setor. Miranda reivindicava a conquista de espaços livres verdadeiramente acessíveis, democráticos e comprometidos com as questões ambientais. Em nenhum momento as condicionantes viárias ou econômicas prevaleceram sobre as demais.

O projeto foi entregue à Emurb com a minuta do projeto de lei e todas as diretrizes de mudanças de usos e dos parâmetros de edificação. $\bigcirc$ perímetro da operação urbana foi completamente revisto, muitas das diretrizes e das propostas acabaram sendo alteradas. $\bigcirc$ desenho proposto para avenida foi parcialmente mantido e aproveitado.

Posso atestar, por minha experiência, que a professora, a pesquisadora e a arquiteta guardam entre si coerência e compromissos que comparecem na prática projetual, na prática profissional de quem indaga, investiga e responde aos compromissos éticos da paisagem.

\section{Nota}

(1) A equipe foi constituída pelos arquitetos coordenadores: Alberto Botti e Miranda Martinelli Magnoli; arquitetos seniores: Ana Maria Antunes Coelho, Fábio Mariz Gonçalves, Luis Mauro Freire; arquitetos: Ana Maria Alvarez G. Peral, Ângela Sbrogio de Almeida, Carla Patrícia Nóbrega, Fernanda Augusta C. A. Pereira, Luis Oliveira Ramos, Simoni Waldman Saidon; estagiária: Renata Machado Franhani; consultores: Lucimar Melo - habitação social, Manoel A. C. Botelho - drenagem, Michel Sola - sistema viário, Millenio Serv. Tec. - Valores imobiliários; serviço administrativo: Elzeli Maria de A. Carneiro, Renata Fialho; desenhos de apresentação: arquiteto Ricardo Flores. 